\title{
Protocol and its Effect on the Continuity of the Argentinian Family Business through Structural Equation Models
}

\begin{abstract}
Family businesses are representative of the economy in Argentina. They are characterized by a strong vocation for continuity as part of the family legacy. However, their permanence has been hindered in most cases by lack of management of the business family. The high rate of disappearance is due in most cases to family-type setbacks.

The family protocol is a tool that contributes to progress of family businesses, facilitating management of the company and the business family. The objective of this work is to find correlation among behaviour of family businesses and the family protocol as a management tool for the permanence of the family business. Structural equations models (SEM) were applied, where on the one hand, the latent variable "continuity"- which indicates the perception that members of family businesses have - was defined and on the other hand, if "having a protocol" has an implication on their endurance.

It is concluded that having a family protocol which includes the guidelines for family and business management contributes to permanence of the family business with all the benefits that this implies both for the business family itself and for the society and economy in which it is immersed.
\end{abstract}

Keywords: Family Businesses; Family Protocol; Structural Equation Models-SEM

Corresponding author: e-mail: director.cef@ucc.edu.ar

Received 18 July 2018 - Accepted 24 Oct 2018

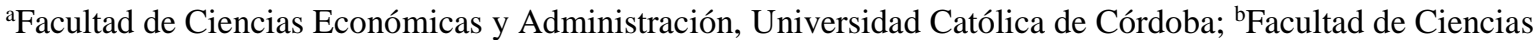
Económicas, Universidad Nacional de Córdoba

This is an Open Access article distributed under the terms of the Creative Commons Attribution-Non-Commercial-No Derivatives License (http://creativecommons.org/licenses/by-nc-nd/4.0/), which permits non-comercial re-use and distribution, provided the original work is properly cited, and is not altered or transformed in any way. 


\section{Introduction}

\section{Presentation of the Research Problem}

According to the Institute of Public Research (1999) cited by the Inter-American Development Bank (2006), in Argentina, 70\% of the companies disappear in the first generation of families, and the same proportion is repeated in the following generations: the children inherit $30 \%$ of the firms and only 5\% reach grandchildren. The memorandum of the Inter-American Development Bank expresses that the main cause of this problem is a lack of knowledge of leaders of family businesses of the importance of having a professional management and family protocol. This statistic follows the same behavior in most of the world.

From our research, we wanted to contribute to the knowledge of this tool in Argentina.

Through exploratory research, we were able to detect that some business families had resorted to protocol to guarantee continuity. However, they also expressed not having obtained said results. In our research, we wanted to delve into the aspects that the protocol must have in order to be an instrument that contributes effectively to continuity.

Amat and Corona (2007) defines the family protocol as a document through which the family members of the company can address the problems that affect its continuity, agreeing on principles and rules whose compliance contribute to a greater family unity and enable the continuity of the company. In this sense, this document assists problems resolution as well as their prevention.

Therefore, the protocol can be understood as an agreement of the wishes of family business members, designed to facilitate management of the family enterprise and to maintain the health and ultimate purpose of each of the components of the company-family system and their resultant superposition. 
In this sense, given the relevance of family businesses and their high level of disappearance; considering as well the adverse consequences that this entails for all the agents involved, our research is oriented to study the contributions of the family protocol as an ideal instrument to achieve preservation of the family business through adequate management.

\section{Hypothesis}

Family protocol contributes to management of family enterprise and business family towards its continuity.

\section{Applied Methodology}

Model of Structural Equations: Concept and contributions of the model

Based on our hypothesis, we searched for a statistical technique that would allow us to arrive to valid conclusions on subjective issues such as family and business management, protocol and continuity. In order to identify relationships between variables (Caballero 2006), the model of structural equations was used. These models are increasingly being disseminated in studies linked to companies, making it possible to investigate areas or processes that are difficult to measure. Cupani (2012) states that the main contribution of this type of models offers researchers the possibility of evaluating theoretical models, becoming one of the most effective tools for the study of causal relationships on non-experimental data in linear relationships. It clarifies that this model contributes to the selection of relevant causal hypotheses, discarding those not supported by empirical evidence. In this sense, it is important to note the theoretical frame to specify the relationship of dependence.

For Ruiz et al. (2010) once the model is estimated it is necessary to evaluate its quality through goodness-of-fit statistics. Likewise, Bojórquez Molina et al. (2013) suggests that the reliability 
of the instrument measurement is necessary and to this end he states that the Alpha of Cronbanch is one of the most used.

\section{Method. Development, Analysis, and Results}

a. Exploratory investigation

The first step, was to identify the management tool that could contribute to continuity. In this way we conducted an exploratory investigation. (Sampieri et al. 2011).

We steered individual interviews with family managers of 15 companies of different sizes and sectors which had between 20 and 1000 employees where each of the interviewees were able to express the main peculiarities of this type of company inherent in business management, family and relations between both. They expressed difficulties that were presented to them when managing competing interests between family and company and how these situations affected the continuity of the organization. They also shared in each case which actions they took to prevent disagreements that could affect the profitability of the firm and / or undermine the permanence of the company in the hands of the business family. Some of these business families had already designed a family protocol to manage relationships between the parties. Six $(40 \%)$ of the interviewees expressed having a protocol and agreed on the fact that they had done it to guarantee the continuity of the family business. However, they expressed that it was not giving them the expected result in most cases.

b. State of the Art

We conducted a thorough investigation of available bibliography of diverse authors from different latitudes and sources. However, we found is scarce literature on protocol, especially from a managerial point of view. 


\section{b. 1. Family protocol-concepts}

Tápies (2011) states that the family protocol becomes a document of vital importance for the purpose of regulating the relationship between corporate and family governance bodies. The concept of family protocol comes from the hand of Ward and Gallo (1991) resulting from strategic planning studies in the family business taken place in the nineties as part of a research stream related to the concept of Corporate Governance in Family Businesses.

Tápies et al. (2011), Sánchez and Crespo (2009), Fernández del Pozo (2008), Favier Dubois (h) and Spagnolo (2013), Bermejo (2008), Trevinyo Rodríguez (2010), Molina Sandoval (2014) define the family protocol from different perspectives with similar characteristics and specific particularities for each business family. All this converges and the family protocol is defined as a tool that allows managing the family and the company, as well as the relationships that arise from them, with the main objective of ensuring the proper functioning of the family-oriented group and sustainable family business growth over time.

According to the working hypothesis, the family protocol is the tool that most contributes to the continuity of family businesses. This instrument allows the parties to be managed, making it possible for each to contribute to the common goal of continuity. It is materialized in a document or agreement, through which the family members can anticipate and channel the problems that affect their permanence, through principles, rules and norms oriented to a greater family unity, perpetuity and strengthening of the company. The protocol thus constitutes an indispensable management tool for the survival of the business family. Its existence and fulfilment generates greater security and trust not only for family members but also with respect to third parties, since owning it implies a code of conduct and acting towards the family and society in general. 
It is necessary to highlight the importance this instrument provides in these organizations, however, its establishment requires predisposition towards dialogue and consensus on the most critical issues, which can undoubtedly be cause of conflicts, on part of the business family.

\section{b. 2. Content of the family protocol}

According to its reality and shared vision, each business family, given the life cycle it goes through, its family evolution and characteristics of its heritage, must take intoaccount different aspects. According to our experience, some aspects will be common to most of them, while others will be specific to each family company. This requires for them to be identified and valued.

Trevinyo Rodríguez (2010) emphasizes the need for the inclusion of minimum key aspects such as those of a moral and legal nature, and includes aspects such as the following: the reasons for doing the protocol we want as a business family; culture and values and their projection in the organization, type of company, expectations, conflictive situations, corporate and family governance bodies, economic rights, organization in the family-company relationship, etcetera. The family protocol will guide the business family allowing planning in a strategic manner according to what was agreed upon in a timely manner. It assumes different concepts, but in essence all agree that it is, in short, an agreement on the issues inherent to the company and the family tending to the permanence and survival of the family business throughout generations. In his research regarding the keys to success of lifelong standing family businesses, Gallo and Amat. (2003) points out among the most important aspects, the development of rules of coexistence and a fluid, spontaneous and frequent communication starting from the family member's childhood. As a corollary to establish the family protocol, he mentions: education of children, stimulation through experiences outside the company, the anticipated development of 
a professional career and prevision of the family organization for the future generation. This topic highlights and reaffirms the importance of the instrument in the durability of family businesses.

To sum up, the protocol as any management tool should be adapted to the type of company in question, regardless of size, generation, etcetera. As long as this instrument allows the company and the family to be managed, the growth of the organization will be possible, and therefore the patrimonial increase of the business family, as well as the family unity. This goal will be achieved through a series of agreements that must be managed and that will make it feasible to establish and delimit the areas of influence between both systems.

Family business protocol is the ideal instrument to manage family business. However, we highlight the importance of the manner in which this contract is elaborated and updated, as well as governing bodies capable of implementing, executing and adapting it to new circumstances. c. Interview with experts.

In order to obtain and deepen relevant information, we conducted in-depth unstructured interviews with experts in the field. In this way we acceded to a greater amount of antecedents, testimonies and foundations through a scheme of open questions devoid of a sequential order, Vargas (2012).

With the exploratory investigation, the state of art and the interview with experts, we elaborated the survey and consequently obtained data that allowed construction of models to validate the hypothesis under study.

d. Data Collection. Survey

From there, we developed the survey for data collection (Pimenta Lastra 2000). This form was the result of the systematization of the information with questions and validation through a 
Likert scale according to the general and specific objectives proposed and the formulation of the research problem.

e. Sampling technique

Given the non-existence in our country of official statistics about family businesses population, our research has been non-probabilistic (Pimienta Lastra 2000). Sampling technique used was casual and the questionnaire was sent by e-mail or paper. Contacts were obtained through the main business chambers, professional associations, and universities to which we have had personal access in most cases. These entities, according to the established guidelines, contributed to access of family organizations. In order to consider the family business typology, we took into account, the following requirements according to the theoretical framework: ownership of the capital belonging mostly to one or more families, decisions making and control of the company in the hands of family members and a strong vocation towards the continuity of this family business in the hands of the following generations.

f. Models of Structural Equations: Estimation strategy

In order to corroborate the hypothesis, we elaborated a business management model and a family management model. Further, we modeled the continuity construct related to the variables of the previous models, and finally we related the continuity with "the fact of having or not a protocol" for the purpose of testing the hypothesis. In all cases we selected the variables that, according to the theoretical framework, exploratory research and interviews with experts, allowed us to measure each of the models.

\section{f. 1. Variables}

At a first stage we identified 54 variables referred to characterize the company, the generations involved, whether or not they had a protocol, its applicability, years of validity, execution. After 
agreeing with a protocol definition, the variables were referred to the process of diagnosis, elaboration, execution and updating. Furthermore, a latent variable was defined: "continuity" that reflects the perception of the family business around this intention. The perception of the phenomenon of survival influences the relevant indicators that were significant after applying dimension reduction techniques (analysis of main components). Table 1 shows the indicators that depend on the latent construct.

Table 1. Defined variables

\begin{tabular}{|c|c|}
\hline Variables Latent & Indicators \\
\hline Continuity & $\begin{array}{l}C 21 \text { : The protocol is valid to anticipate conflicts. } \\
C 22 \text { : The protocol contributes to the resolution of } \\
\text { conflicts. } \\
C 24 \text { : The protocol favours maintaining healthy } \\
\text { bonds within the business family. } \\
C 25 \text { : The protocol contributes to the prolongation of } \\
\text { the lifecycle of the company } \\
C 31 \text { : Values, tradition, culture and principles are } \\
\text { elements of indispensable importance to be reflected } \\
\text { in the protocol. } \\
C 32 \text { : It is transcendental that all members of the } \\
\text { family agree with the type of company they want. } \\
\text { (Shared vision) } \\
C 35 \text { : It is necessary to define the business and family } \\
\text { management bodies } \\
C 41 \text { : It is advisable to incorporate all types of rules } \\
\text { that allow managing the company-family } \\
\text { relationship. } \\
\text { Protocol (having it or not) }\end{array}$ \\
\hline
\end{tabular}




\section{f. 2. Model}

Models of Structural Equations (SEM) were applied in search for causal analysis between the actions of members of family businesses in relation to family protocol as a business and family management tool for continuity of the family business.

SEM began to extend from 1973, when the LISREL analysis program (Linear Structural Relations, Jöreskog 1973) emerged, which was the initial kick off because they are complex models that require a high computational capacity. These models are used to construct explanatory schemes, that is, theories that enable a better understanding of the reality and of the observed phenomena through quantitative tests, which determine to what extent the data of a sample supports a theoretical model of multiple relations of dependence between variables, proposed in contrast by the researcher (Ruiz et al. 2010).

The SEM are a family of multivariate statistical models which allow estimating the effect and relationships between multiple variables. They have the advantage of providing greater flexibility to regression models, since they are less restrictive due to the fact that they allow inclusion of mean errors in both dependent and independent variables. In these models, the aim is to adjust the covariance between the variables, that is, to minimize the difference between the covariance observed in the sample and the covariance estimated by the structural model. This idea is summarized in the following equation:

$$
\text { Ho: } \Sigma=\Sigma(\theta)
$$

where,

$\Sigma$ : population variance-covariance matrix among the variables observed

$\Sigma(\theta)$ : estimated variance-covariance matrix derived as a function of the parameters contained in the vector $\theta$. 
Cupani (2012) states this type of models allows us to simultaneously analyse a series of dependency relationships between variables with the particularity that it allows for its study when a dependent variable becomes independent in subsequent dependency relationships. The model contributes to the selection of relevant causal hypotheses, with the theoretical support for the specification of these dependency relationships.

Once the model has been estimated it is necessary to evaluate its quality through goodness-offit statistics (Ruiz et al. 2010).

These models can be denoted through their analytical expressions or graphically. For example, ${ }^{1}$

$x_{1}=\alpha_{1}+\beta_{1} X+e x_{1}$

$x_{2}=\alpha_{2}+\beta_{2} X+e x_{2}$

$x_{3}=\alpha_{3}+\beta_{3} X+e x_{3}$

$x_{4}=\alpha_{4}+\beta_{4} X+e x_{4}$

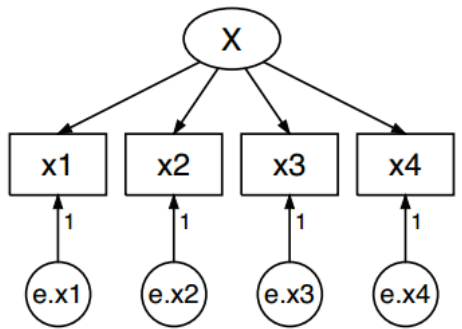

Cronbach's alpha was used as a measure of internal consistency in order to estimate the reliability of a measurement instrument through a set of items that are expected to measure the same construct or theoretical dimension. In this way, the validity of the data collection instrument was tested, which measures what it intends to measure. The measure of reliability using Cronbach's alpha assumes that the items on a Likert scale acquire the same construct and are highly correlated. The closer the value of alpha to 1 is, the greater the internal consistency of the items analysed is. Reliability of the scale must always be obtained with the data of each sample to guarantee reliable measurement of the construct in the specific research sample.

1 Source Stata v.14 
This research is based on the assumption that the family protocol contributes to permanence of the company, it should reflect shared vision, values, culture, tradition and principles that will be a guide for business management. For the purposes of good management, it is necessary to define the corporate governance bodies that function actively according to the purpose created, as well as the family governance bodies that allow managing the business family, so that they constitute a bridge between the company and the family, preventing one of the parts of the binomials from advancing on the other.

A model was built, based on the theoretical framework and expert interviews. It includes the mentioned indicators, the Protocol variable and two parameters that contributed to a good fit of the model to the data set were added. The covariance between $\mathrm{C} 21-\mathrm{C} 25$ and $\mathrm{C} 22-\mathrm{C} 35$ are added. Establishing norms and agreements, through the protocol, allows anticipating conflicts (C21), which will imply a contribution to the prolongation of the family business (C25) over time. This instrument will also allow, where appropriate, to resolve problematic situations (C22), for which it will be necessary to define the business and family management bodies (C35) that make it possible to carry them out concretely. The formalization of the model is:

$$
\begin{gathered}
C 21=\alpha_{1}+\beta_{1} \text { Cont }+e C 21 \\
C 22=\alpha_{2}+\beta_{2} \text { Cont }+e C 22 \\
C 24=\alpha_{3}+\beta_{3} \text { Cont }+e C 24 \\
C 32=\alpha_{4}+\beta_{4} \text { Cont }+e C 32 \\
C 35=\alpha_{5}+\beta_{5} \text { Cont }+e C 35 \\
C 41=\alpha_{6}+\beta_{6} \text { Cont }+e C 41 \\
C 25=\alpha_{7}+\beta_{7} \text { Cont }+e C 25 \\
C 31=\alpha_{8}+\beta_{8} \text { Cont }+e C 31 \\
\text { Cont }=\alpha_{9}+\beta_{9} \text { Protocolo }+e C o n t \\
\sigma_{e C 21 ; e C 25}=\sigma_{e C 25 ; e C 21}=0 \\
\sigma_{e C 22 ; e C 35}=\sigma_{e C 35 ; e C 22}=0
\end{gathered}
$$




\section{f. 3. Modeling}

\section{f. 3. 1. Business Management Model.}

The indicators that are influenced by the perception about business management are: C25 The protocol contributes to the extension of the lifecycle of the company.

Figure 1. Business management model

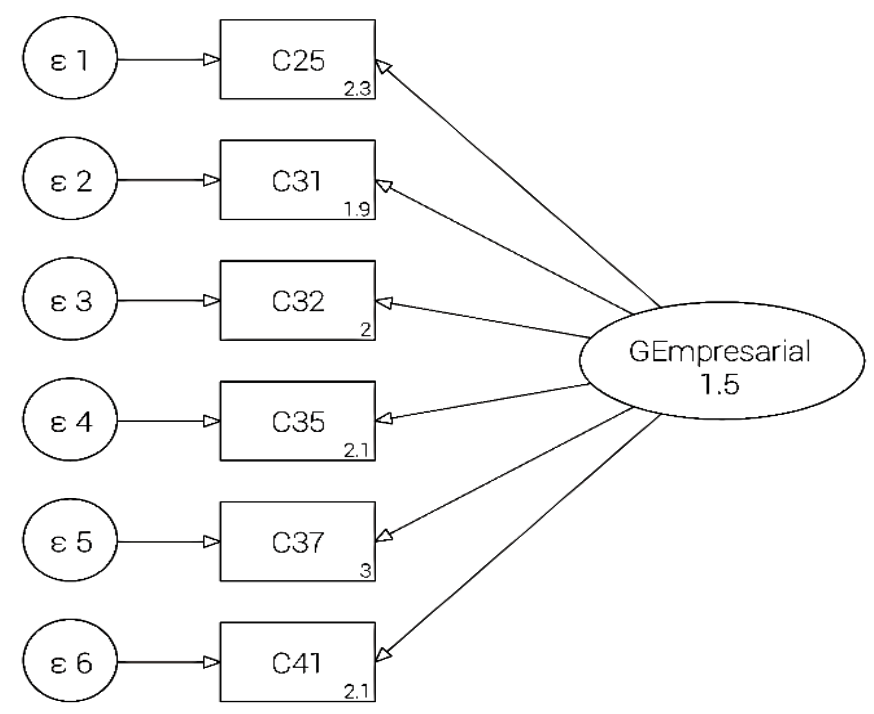

C31 Values, tradition, culture and principles are elements of indispensable importance to be reflected in the protocol. C32 It is transcendental that all members of the family agree with the type of company they want. (Shared vision). C35 It is necessary to define the business and family management bodies. C37 Succession planning is the topic of the highest hierarchy. C41 It is advisable to incorporate all kinds of rules that allow managing the relationship companyfamily. Cronbach's Alpha was calculated and the result was 0.8727 , a very good scale to measure what is desired. The relationships (P-value) were all significant. This shows that there is a positive perception of all the variables in relation to business management. The measures of goodness of fit presented acceptable values. SRMR (Standardized root mean residual square) 0.022 and RMSEA (Root mean square error of approximation) 0.01 . 
We can conclude from the data stated above: The family protocol positively affects business management as it contributes to the continuity of the company over time through the transmission of values, culture, tradition and principles. It is necessary that the shared vision of the business family be reflected in the desired organization; it becomes important to define both corporate and family governing bodies as well as planning for the generational transition and any rule that regulates family business links.

\section{f. 3. 2. Family Management Model.}

The indicators that are influenced by their perception of family management are: C21 The protocol is valid to anticipate conflicts. C22 The protocol contributes to the resolution of conflicts. C24 The protocol favors maintaining healthy links within the family business.C32 It is crucial that all family members agree with the type of company they want (shared vision). C35 It is necessary to define the corporate and family governance bodies. C41 It is advisable to incorporate all types of rules that allow managing the company-family relationship. Cronbach's Alpha was calculated and the result was 0.9060 , which indicates that the scale is adequate. Pvalues were significant as well as the measures of goodness of fit.

Figure 2. Family business model

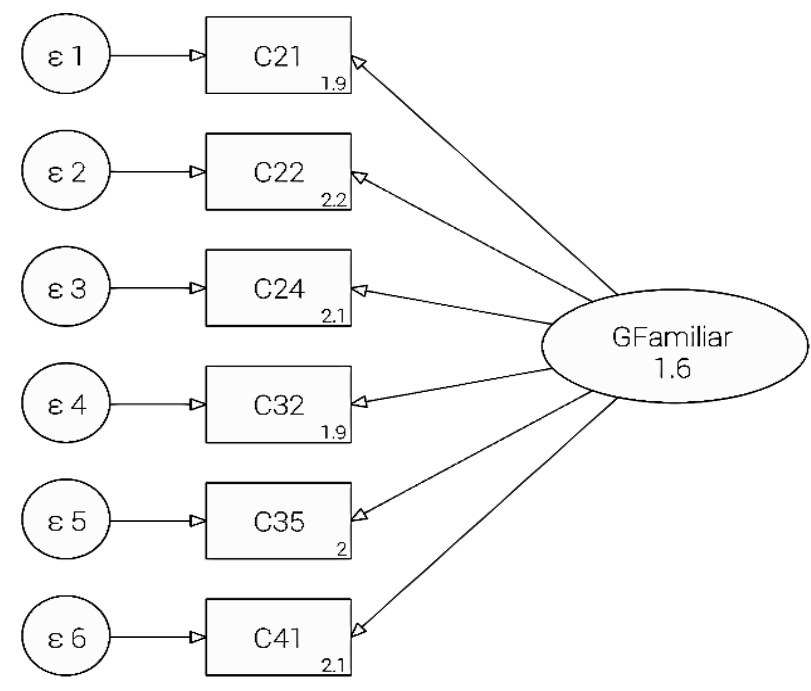


The protocol is a good instrument for family management since it allows to anticipate and, when necessary, to resolve conflicts; favoring maintaining healthy family ties. Through this instrument, members of the business family capture the shared vision about the type of company they wish to have. Therefore, establishing all kinds of rules that regulate the family business relationships acquires special significance. To define corporate and family governance bodies will contribute positively to family management.

\section{f. 3. 3. Model that includes Continuity (Continuity Model)}

Attending to the variables of the business and family management constructs, we elaborated the continuity construct in order to build a model that relates both managements to the vision of the prolongation of the family company. We added variable C25 to this model: The protocol contributes to the extension of the lifecycle of the company.

Figure 3. Continuity model

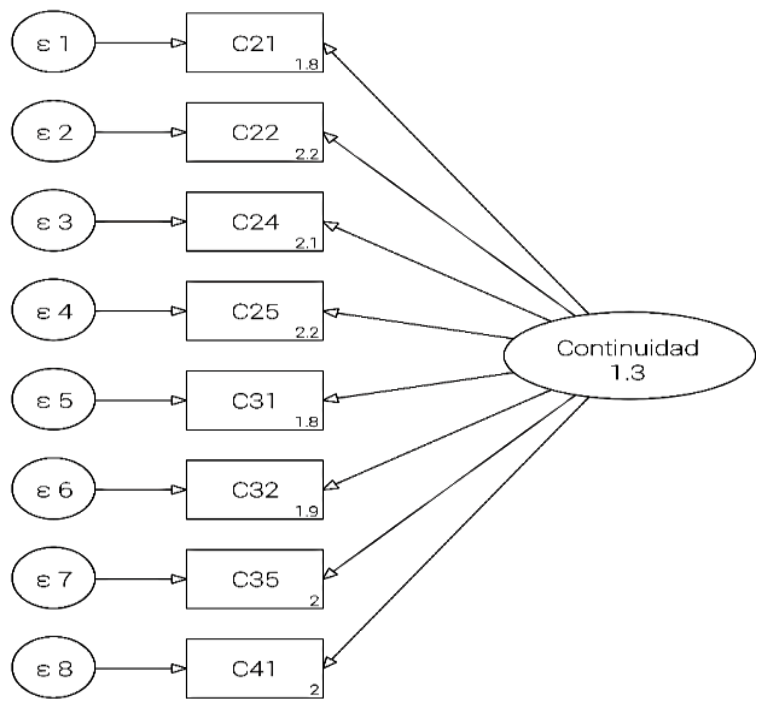

The Cronbach's Alpha was calculated and the result was 0.9338 , which means that it is a good scale of measurement. All significant relationships (P-value) are observed, which means that the continuity construct is positively reflected in the defined indicators. Since all measures of 
goodness of adjustment (RMSEA and the SRMR) were accepted, I would affirm that the model is adequate.

f. 3. 4. Model for the continuity of the company with a protocol (Protocol Model)

Next, we added to the model the variable "having a protocol" and its importance for continuity. From the modeling performed, it was necessary to add two parameters in order for a better fit to the data set and contribution to the fulfillment of the hypotheses, in this case, the covariance between C21 and C25, C22 and C35 were added. Establishing norms and agreements through the protocol allows anticipating conflicts $(\mathrm{C} 21)$, which will imply a contribution to the extension of the family business (C25) over time. This instrument will also allow, when appropriate, to resolve problematic situations (C22), for which it will be necessary to define business and family management bodies (C35) that make it possible to specifically carry them out.

Figure 4. Protocol model

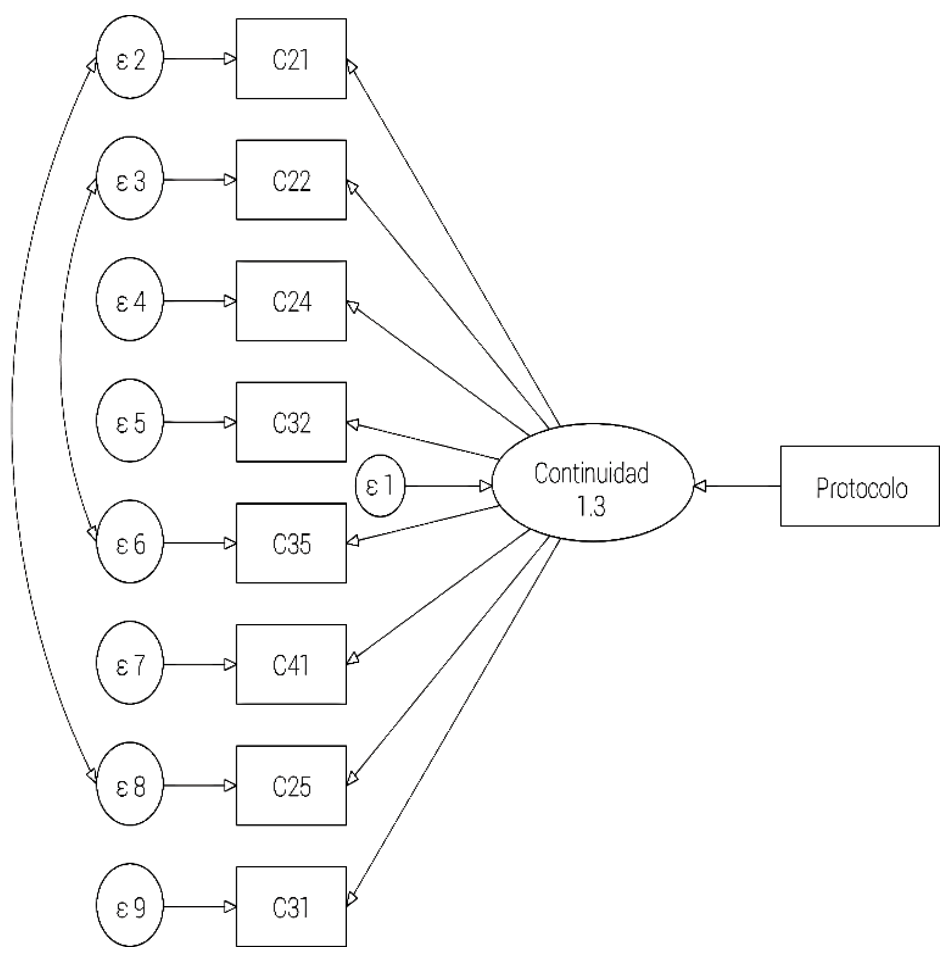


Cronbach's Alpha throws a value of 0.9338 , which would indicate that what is desired is measured. The measurements of goodness of fit showed that relationships are significant. That is, continuity is reflected positively in the indicators. It is important to highlight the significant relationship between having or not having a protocol with the continuity construct, which indicates that having a family protocol positively affects continuity of the company.

The values of $p$-value shows us the approval of the hypotheses. Having a family protocol contributes to the continuity of the family business.

Regarding the measures of goodness of fit, it shows a value affirmed by RMSEA and SRMR. Having a family protocol which includes the guidelines for family and business management will contribute to the continuity of the family business with all the benefits that this implies for business family itself and for the society and economy in which it is immersed. The guidelines that have been defined in each of the variables should be consistent with the life cycle of the company and the size of the business family and its heritage.

\section{g. Results}

The main variables that link instrument with continuity refer to business management in that it contributes to the extension, allows to capture values, culture, traditions and principles, including succession planning on the one hand, and family management in how much is valid to anticipate and resolve conflicts and favours to maintain healthy links, on the other hand.

Common to both procedures are shared vision, definition of corporate and family governance bodies and the possibility of including all kinds of rules that allow the company-family to be managed.

The Alpha of Cronbach yields a value of 0.9338 indicating it is a very good instrument that captures what is intended to be measured. 
As shown in Table 2, the relationships are significant, meaning progress is reflected positively in the indicators.

It is important to highlight the significant relationship between having or not having a protocol with the continuity construct, which would indicate that investing in a family protocol positively affects the progress of the company.

The probability values (p-value) show us that the observed indicators are significantly affected by the latent variable: "continuity", which is on the other hand influenced by having a protocol.

Table 2. Relations of the model

\begin{tabular}{|c|c|c|c|}
\hline Ratio & Coefficient & Statistical & p-value \\
\hline C21 <Continuity* & 1 & 4,23 & 0,000 \\
\hline C22<Continuity & 0,8345 & 14,27 & 0,000 \\
\hline C24 < Continuity & 1,0409 & 14,02 & 0,000 \\
\hline C32 <Continuity & 1,0354 & 9,37 & 0,000 \\
\hline C35 < Continuity & 1,0195 & 13,9 & 0,000 \\
\hline C41 <Continuity & 0,8813 & 9,87 & 0,000 \\
\hline C25 < Continuity & 1,0481 & 13,19 & 0,000 \\
\hline C31<Continuity & 1,0423 & 10,80 & 0,000 \\
\hline Protocol <- continuity & 0,37 & 2,28 & 0,022 \\
\hline Cov ( C21,C25) & -.122945 & $-2,5$ & 0,01 \\
\hline $\operatorname{Cov}(\mathrm{C} 22, \mathrm{C} 35)$ & -.122014 & $-2,7$ & 0,007 \\
\hline
\end{tabular}

Test of the model vs the saturated model $p=0.05$

The probability value (p) is 005 , this limit value indicates the hypothesis that the data reproduces the variance and covariance matrix of the population is not rejected. 
This is confirmed with the measures of goodness of fit, the approximation of the root of the mean square error (RMSEA) that measures how much error exists per degree of freedom and the root of the standardized residual mean square error (SRMR) that measures how close each correlation can be reproduced, on average. The first one yields an acceptable value and the second one a good adjustment.

Table 3. Measures of goodness of fit

\begin{tabular}{|l|l|}
\hline Measures of goodness of fit & Value \\
\hline SRMR & 0,057 \\
\hline RMSEA & 0,048 \\
\hline
\end{tabular}

Having a family protocol which includes the guidelines for family and business management will contribute to the continuity of the family business with all the benefits that this implies both for the business family itself and for the society and economy in which it is immersed.

The guidelines that have been defined in each of the variables should be consistent with the life cycle of the company and the size of the business family and its heritage.

\section{Conclusions}

According to the stated hypothesis: "Family protocol contributes to the management of the family enterprise and the business family towards its continuity" and given the results of our research we are able to affirm that the family protocol is a business and family management tool that contributes to permanence. We must clarify that this statement is valid for the companies surveyed. Recall that one of the limitations of our research is not to have the population of Argentine family businesses. However, the results obtained encourage us to expand our sample in the future and work on obtaining population data on family companies in our country. 
Relevance of family businesses in the capitalist economies of the West is known, since they make up a high percentage of the business collective contributing to the economy, society and region in which they are immersed. Likewise, it is known its high level of disappearance is generated mainly by conflicts that derive from the coexistence of the company and family systems, causing highly negative impacts at the macro, micro level and for the own business family.

This work intends to contribute to the progress of these companies in the hands of the following generations promoting the growth of the organization along with healthy family ties. In that sense we proposed to demonstrate that the family protocol is the ideal tool as long as it complies with certain factors at both the business and family levels. These variables were identified by the models, affirming the proposed hypothesis. It should be noted that as any management tool, the family protocol should conform to guidelines for development, implementation, control and feedback for its proper functioning. Additionally, someone in charge of management and communication and participation of those involved is essential to its proper functioning.

\section{References}

Amat, Joan, and Juan Fernando Corona. 2007. El Protocolo Familiar. La experiencia de una década. Barcelona: Deusto Editions.

Bermejo Manuel. 2008. Hacia la Empresa Familiar Líder. España: FT Prentice Hall.

Bojórquez Molina José, Lina López Aranda, María Hernández, and Eusebio Jiménez López. 2013. “Use of Cronbanch's alpha to validate the reliability of measuring student satisfaction in the use of Mintab software." Cancún Mexico. Innovation in Engineering Technology and Education for competitiveness and Prosperty. Agust 14-16.

Caballero Domingo, Antonio J. 2006. "SEM versus PLS: A practice-based approach." Complutense University of Madrid. IV Congreso de Metodología de encuestas. Pamplona, Spain, September 20-22. 
Cupani, Marcos. 2012. "Análisis de ecuaciones estructurales: conceptos, etapas de desarrollo y un ejemplo de aplicación.” Revista Tesis 1:186 -199.

Favier Dubois, Eduardo (h) and Lucia Spagnolo. 2013. Herramientas Legales para la empresa familiar. Argentina: Ad Hoc.

Fernandez del Pozo, Luis. 2008. El Protocolo Familiar. España: Thomson Civitas

Gallo, Miguel Angel, and Joan Amat. 2003. Los secretos de las empresas familiares centenarias. Barcelona: Deusto.

Inter-American Development Bank. 2006. Memorando: Promover la supervivencia y competitividad de las empresas familiares de la Región Centro 1-8 (AR-M1020)

Jöreskog, Karl G. 1973. "A general method for estimating a linear structural equation System.” In Structural Equation Models in the Social Sciences, edited by Goldberger, and O.D. Duncan, 85-112. New York: Seminar. A.S.

Molina Sandoval, Carlos. 2014. Empresas Familiares Herramientas de planificación y profesionalización. Buenos Aires: Erreius.

Sanchez, Antonio, and Crespo Casanova. 2009. El Protocolo Familiar. Madrid: Gofer.

Siampietri Hernandez, Roberto, Carlos Fernandez Collado, and Lucio Baptista. 2011. Metodología de la investigación (IV edición). México: McGrae Hill.

StataCorp. 2015. Stata Statistical Software: Release14. College Station, TX: Stata CorpLP 2-34

Pimienta Lastra, Rodrigo. 2000. “Encuestas Probabilísticas versus no probabilísticas. Universidad Autónoma Metropolitana.” Unidad Xochimico. Política y Cultura 13:263-276.

Ruiz, Miguel, Antonio Pardo, and Rafael San Martín. 2010. "Models of Structural Equations.” Papers of the psychologist 31:34-45.

Tápies, Josep. 2011. Familia Empresaria. Madrid: LID Editorial Empresarial.

Trevinyo Rodríguez, Rosa N. 2010. Empresas Familiares. México: Visión Latinoamericana Pearson. Vargas Jiménez, Ileana. 2012. "The interview in qualitative research: new trends and challenges." Quality Magazine in Higher Education 3:119-139.

Ward, John, and Miguel Gallo. 1991. "Nota Técnica de la división de Investigación del IESE Cátedra de Empresa Familiar." Revista Marzo1993- DGN-448.

\footnotetext{
This is an Open Access article distributed under the terms of the Creative Commons Attribution-Non-Commercial-No Derivatives License (http://creativecommons.org/licenses/by-nc-nd/4.0/), which permits non-comercial re-use and distribution, provided the original work is properly cited, and is not altered or transformed in any way.
} 